\section{Salvage of a Free Flap Using Postoperative Percutaneous Angioplasty in Patients with Diabetic Foot Ulcers}

Joo Youn $\mathrm{Kim}^{1}$, Hyun Gon $\mathrm{Choi}^{1}$, Ki Il Uhm ${ }^{1}$, Soon Heum Kim², Cheol Keun Kim², Dong in $\mathrm{Jo}^{2}$, Dong Hyeok Shin

${ }^{1}$ Department of Plastic and Reconstructive Surgery, Konkuk University Medical Center, Konkuk University School of Medicine, Seoul; ${ }^{2}$ Department of Plastic and Reconstructive Surgery, Konkuk University Chungju Hospital, Konkuk University School of Medicine, Chungju, Korea

Correspondence: Dong Hyeok Shin

Department of Plastic and Reconstructive Surgery, Konkuk University Medical Center, Konkuk University School of Medicine, 120-1 Neungdong-ro, Gwangjin-gu, Seoul 143-729, Korea

Tel: +82-2-2030-5235, Fax: +82-2-2030-5249

E-mail: sdhplastic@kuh.ac.kr

No potential conflict of interest relevant to this article was reported.

Received: 10 Jun 2014 • Revised: 22 Jun 2014 • Accepted: 1 Jul 2014 pISSN: 2234-6163 • elSSN: 2234-6171

http://dx.doi.org/10.5999/aps.2014.41.6.788 • Arch Plast Surg 2014;41:788-790 Copyright (C) 2014 The Korean Society of Plastic and Reconstructive Surgeons This is an Open Access article distributed under the terms of the Creative Commons Attribution Non-Commercial License (http://creativecommons.org/licenses/by-nc/3.0/) which permits unrestricted non-commercial use, distribution, and reproduction in any medium, provided the original work is properly cited.

Although microsurgical reconstruction of the diabetic foot has shown high success rates in recent studies, it remains challenging in patients with peripheral arterial disease (PAD) [1]. Free flap surgery should be performed in $\mathrm{PAD}$ patients after establishing blood flow preoperatively by using percutaneous transluminal angioplasty (PTA) or bypass surgery $[1,2]$. However, even after successful revascularization, intraoperative spasm or thrombosis of the recipient artery can occur, and unless resolved before anastomosis, it may lead to flap failures [3]. Herein, we report 2 cases of prolonged recipient arterial compromises that occurred abruptly after donor flap harvest. We solved these situations by performing PTA postoperatively, and this report describes our experience.

Patient 1 was a 74-year-old woman with a diabetic ulcer on her third and fourth toes on the left. Serial debridement resulted in a $4 \times 5-\mathrm{cm}$ open wound with the exposure of the third and fourth metatarsal bones (Fig. 1A). Preoperative angiography showed multifocal stenoses throughout the lower extremity vasculature, including the left dorsalis pedis artery (DPA) and metatarsal arteries. Successful revascularization with PTA was performed by an interventional radiologist (Fig. 2A). Three weeks later, anterolateral thigh free flap was used to cover the skin defect of the left foot. Pulsatile flow in the DPA was assessed using intraoperative Doppler and clinical inspections. The calcified portion of the DPA was resected, and the flow-through flap was harvested from the patient's thigh. After removal of the microvascular clamp before anastomosis, the DPA became thrombotic; therefore, we performed thrombectomy using the Fogarty catheter. The thrombosis resolved, but spasms were observed even after irrigation with heparin and papaverine. Once flow-through anastomosis was completed, the flap showed several signs of compromise and poor Doppler signals. As we could not find another recipient vessel, we planned to revascularize the recipient artery postoperatively, and then complete the operation. After 13 hours, we revascularized the completely occluded DPA (Fig. 2B) using a 1.5-mm balloon catheter and checked active flap blood flow
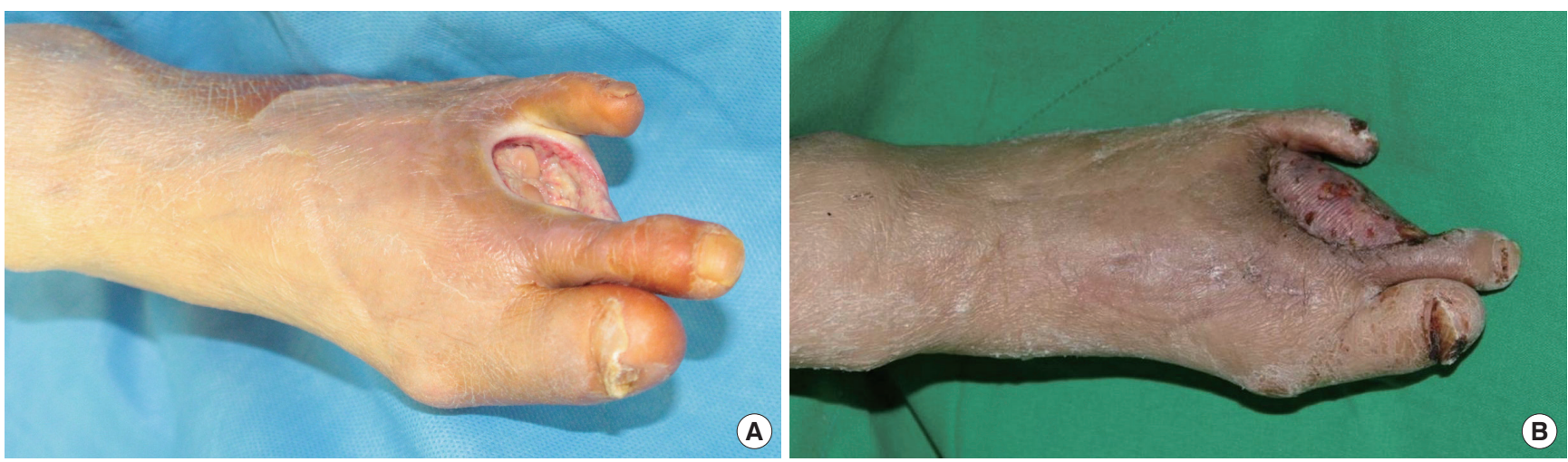

Fig. 1.

Photography of patient 1. (A) Preoperative view showing diabetic ulceration on the left foot. (B) Postoperative view at 6 weeks, following reconstruction with anterolateral thigh free flap. 

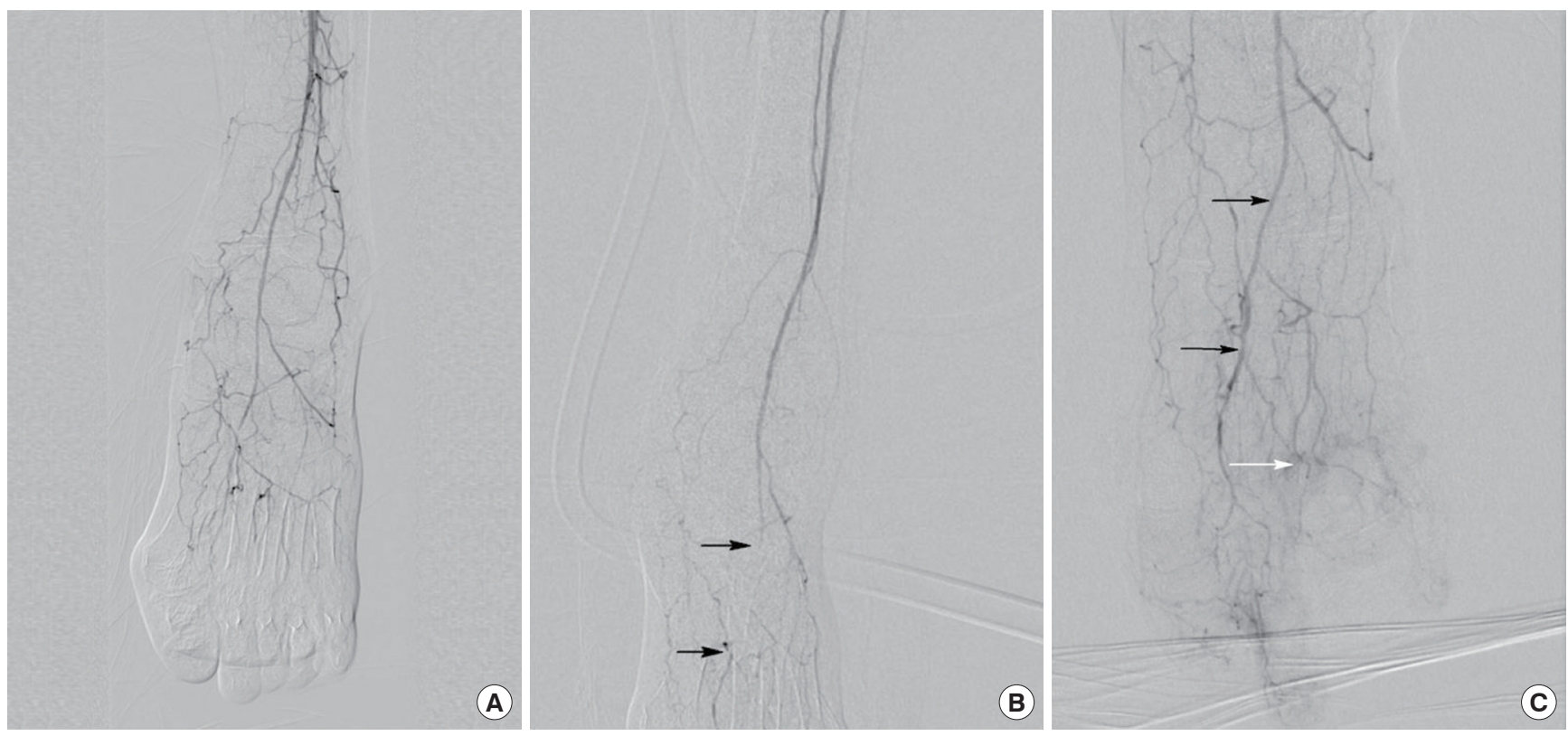

Fig. 2.

Angiography of patient 1. (A) Preoperative angiogram showing the patent dorsalis pedis artery. (B) Postoperative angiogram before percutaneous transluminal angioplasty (PTA) showing total occlusion of the dorsalis pedis artery (black arrows). (C) Postoperative angiogram after PTA showing the revascularized dorsalis pedis artery (black arrows) and excellent blood flow into the flap (white arrow).

on angiography (Fig. 2C). At the end of the procedure, the pale flap became pinkish and showed pulsatile Doppler signals. However, partial necrosis of the flap was noticed, which was later covered with skin graft (Fig. 1B). The patient was discharged without complications 2 weeks after the skin graft.

Patient 2 was a 74 -year-old man with a chronic diabetic ulcer on his big toe on the right since 5 months ago. Preoperative angiography showed total occlusion of the right DPA and stenosis of the distal posterior tibial artery; these affected arteries were revascularized using PTA. Reconstructive surgery using anterolateral thigh perforator flap was performed to cover a $3 \times 4-\mathrm{cm}$ open wound on the bottom of the right big toe by using the first plantar metatarsal artery (PMA) as the recipient artery. After donor flap harvesting, the pulsatile bleeding from the PMA stopped abruptly. Accordingly, we attempted adventitia stripping, intraluminal heparin and papaverine irrigation, and Fogarty catheterization of the PMA, but failed to restore pulsatile flow in the recipient artery. Given similar circumstances to that in patient 1's case, we planned postoperative PTA and continued the operation. The donor artery was anastomosed to the PMA in an end-to-side manner, and patient 2 was immediately sent to the intervention room after the operation. Conventional angiography showed total occlusion of the PMA proximal to the anastomosis site, and was successfully revascularized using a $1.5-\mathrm{mm}$ balloon catheter by an interventional radiologist. The flap became pink, and blood was seen on a pinprick immediately after PTA, indicating no signs of compromise on flap monitoring. Two weeks later, the patient was discharged with good flap contour.

In reconstruction of diabetic foot ulcers, many surgical options such as secondary intention, local flaps, skin grafts, pedicled flaps, and free tissue transfer can be used. The reconstruction should provide durability, sound protection, and good contour for patients. For these purposes, the flap surgery may be ideal. However, local flaps or pedicled flaps could be impossible or harmful for a certain vascular status in patients with $\mathrm{PAD}$. In this reason, we chose the reconstruction using free flap surgery in present cases.

When choosing and preparing recipient arteries, spasm and thrombosis are major contributing factors in free flap loss [3]. Spasms can be managed with warm solutions, spasmolytic agents, lidocaine, adventitial stripping or Fogarty catheter, and thrombosis can be managed with manual milking, irrigation with heparinized solution, or reanastomosis [4].

In our cases, despite various salvage methods, vascular compromises did not resolve intraoperatively. 
In these situations, free flap surgery may be replaced with a different procedure, such as skin grafting. However, as both our patients had recipient arteries with good pulsatile flow before donor flap harvest, we elected to proceed with planned flap surgery and postoperatively, attempted revascularization of the recipient arteries with angioplasty.

Anavekar et al. [5] reported 2 successful cases of flap salvage using endovascular thrombolysis with angioplasty balloon and urokinase in patients with late compromise flaps. In our cases, flap compromises resolved after complete revascularization of recipient arteries using PTA immediately after the surgery.

In general, PTA is indicated in patients with diabetic foot ulcers and $>50 \%$ occlusion in the peripheral arterial tree, but is also feasible in cases of calcified, $>10 \mathrm{~cm}$, or multiple stenoses or occlusions. PTA can be performed without any contraindications even in patients with high surgical risks, and complications associated with this procedure are rare. Moreover, PTA can be successfully repeated in cases of restenosis, reocclusion, or after bypass failure [2]. In both our cases, we restored blood flow into the flaps by performing PTA postoperatively without mechanical injuries at the sites of anastomoses.

To our knowledge, this is the first report to describe the postoperative PTA as a salvage alternative for intraoperative vascular compromise in free flap surgery. All flaps survived successfully, although one case of partial necrosis required skin grafting. Postoperative PTA for flap salvage is not routinely recommended under usual circumstances; however, it could be an alternative in extremely challenging cases.

\section{References}

1. Oh TS, Lee HS, Hong JP. Diabetic foot reconstruction using free flaps increases 5-year-survival rate. J Plast Reconstr Aesthet Surg 2013;66:243-50.

2. Faglia E, Mantero M, Caminiti M, et al. Extensive use of peripheral angioplasty, particularly infrapopliteal, in the treatment of ischaemic diabetic foot ulcers: clinical results of a multicentric study of 221 consecutive diabetic subjects. J Intern Med 2002;252:225-32.

3. Chaivanichsiri P. Influence of recipient vessels on free tissue transplantation of the extremities. Plast Reconstr Surg 1999;104:970-5.

4. Egozi D, Fodor L, Ullmann Y. Salvage of compromised free flaps in trauma cases with combined modalities. Microsurgery 2011;31:109-15.

5. Anavekar NS, Lim E, Johnston A, et al. Minimally invasive late free flap salvage: indications, efficacy and implications for reconstructive microsurgeons. J Plast Reconstr Aesthet Surg 2011;64:1517-20.

\section{A New Method for Forming the Pretarsal Fullness after Lower Blepharoplasty}

Jae Hoon Shin ${ }^{1}$, Chan Min Chung ${ }^{1}$, In Pyo Hong ${ }^{1}$, Hyung Joo Lee ${ }^{2}$, JI Eun Baek ${ }^{2}$

${ }^{1}$ Department of Plastic and Reconstructive Surgery, National Medical Center, Seoul; ${ }^{2}$ Lee Hyung Joo Aesthetic Clinic, Daejeon, Korea

Correspondence: In Pyo Hong

Department of Plastic and Reconstructive Surgery, National Medical Center, 245 Eulji-ro, Jung-gu, Seoul 100-799, Korea

Tel: +82-2-2260-7207, Fax: +82-2-2272-7207

E-mail:nmcps@unitel.co.kr

No potential conflict of interest relevant to this article was reported.

Received: 11 Jul 2014 • Revised: 7 Aug 2014 • Accepted: 18 Aug 2014 pISSN: 2234-6163 • elSSN: 2234-6171

http://dx.doi.org/10.5999/aps.2014.41.6.790 • Arch Plast Surg 2014;41:790-792 Copyright (c) 2014 The Korean Society of Plastic and Reconstructive Surgeons This is an Open Access article distributed under the terms of the Creative Commons Attribution Non-Commercial License (http://creativecommons.org/licenses/by-nc/3.0/) which permits unrestricted non-commercial use, distribution, and reproduction in any medium, provided the original work is properly cited.

Patients with lower eyelid aging may frequently have a dull appearance with no facial expression rather than a younger, healthy and sweet one after the removal of the orbital fat bulging, resection of the redundant skin and orbicularis oculi muscle (OOM) (Fig. 1). This is because the pretarsal fullness disappears or becomes flattened or depressed after lower blepharoplasty. To resolve this, many local clinics perform various procedures for re-creating the pretarsal fullness after

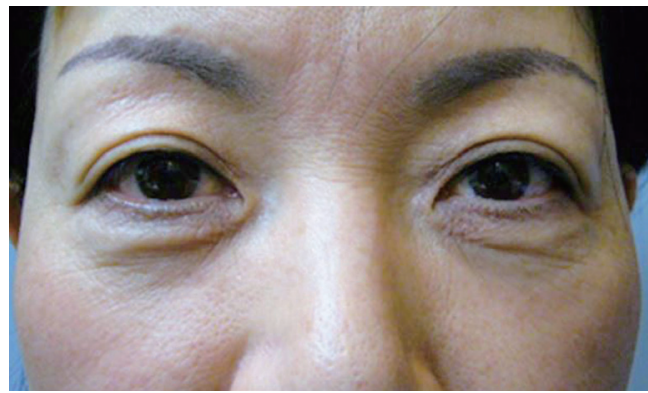

Fig. 1.

A 45-year-old woman with palpebral bag and tear trough grooves. 